Marquette University

e-Publications@Marquette

$12-7-2016$

\title{
The Effect of Mo Doping on The Charge Separation Dynamics and Photocurrent Performance of $\mathrm{BiVO}_{4}$ Photoanodes
}

\author{
Brian Pattengale \\ Marquette University \\ Jier Huang \\ Marquette University, jier.huang@marquette.edu
}

Accepted version. Physical Chemistry Chemical Physics, Vol. 18, No. 48 (December 7, 2016):

32820-32825. DOI. (C) 2016 Royal Society of Chemistry. Used with permission. 


\title{
Marquette University
}

\section{e-Publications@Marquette}

\section{Chemistry Faculty Research and Publications/College of Arts and Sciences}

This paper is NOT THE PUBLISHED VERSION; but the author's final, peer-reviewed manuscript. The published version may be accessed by following the link in th citation below.

Physical Chemistry Chemical Physics, Vol. 18, No. 48 (December 7, 2016): 32820-32825. DOI. This article is (C) Royal Society of Chemistry and permission has been granted for this version to appear in ePublications@Marquette. Royal Society of Chemistry does not grant permission for this article to be further copied/distributed or hosted elsewhere without the express permission from Royal Society of Chemistry.

\section{The Effect of Mo Doping on The Charge Separation Dynamics and Photocurrent Performance of $\mathrm{BiVO}_{4}$ Photoanodes}

\author{
Brian Pattengale \\ Department of Chemistry, Marquette University, Milwaukee, WI \\ Jier Huang \\ Department of Chemistry, Marquette University, Milwaukee, WI
}

\section{Abstract}

Doping with electron-rich elements in $\mathrm{BiVO}_{4}$ photoanodes has been demonstrated as a desirable approach for improving their carrier mobility and charge separation efficiency. However, the effect of doping and dopant concentration on the carrier dynamics and photoelectrochemical performance remains unclear. In this work, we examined the effects of Mo doping on the charge separation dynamics and photocurrent performance in $\mathrm{BiVO}_{4}$ photoanodes. We show that the photocurrent of $\mathrm{BiVO}_{4}$ photoanodes increases with increasing concentration of the Mo dopant, which can be attributed to both the improved carrier mobility resulting from 
increased electron density and charge separation efficiency due to the diminishing of trap states upon Mo doping. The effect of doping on the electronic structure, carrier dynamics and photocurrent performance of $\mathrm{BiVO}_{4}$ photoanodes resulting from $\mathrm{W}$ and Mo dopants was also compared and discussed in this study. The knowledge gained from this work will provide important insights into the optimization of the carrier mobility and charge separation efficiency of $\mathrm{BiVO}_{4}$ photoanodes by controlling the dopants and their concentrations.

\section{Introduction}

The development of efficient photoelectrode materials for the production of carbon-neutral and sustainable fuel sources by solar-driven water splitting is an urgent need to meet long-term global energy demands. ${ }^{1-5}$ Despite the tremendous progress achieved towards the development of such photoelectrodes, it still remains a challenging task to develop a material that can meet the multiple resource intensive requirements of the solar-driven photocatalytic reactions. -9 This particular challenge results from the oxidative half reaction, i.e. water oxidation to form protons and oxygen (OER), which requires a high overpotential and is considered as the bottleneck for artificial photosynthetic water splitting. Extensive efforts have thus been devoted to developing efficient photoanode materials for OER in the past decade. $\frac{10-17}{17}$

$\mathrm{BiVO}_{4}$, owing to its moderate band gap (2.4 eV), ,18.19 capability to absorb visible light, 20.21 high stability in aqueous solution,, 1722 as well as its significantly more positive valence band edge than the OER potential, $22-24$ has become the most promising photoanode material. Regardless of its multifold benefits as a photoanode material, the performance of bare $\mathrm{BiVO}_{4}$ for OER is not impressive. The key factors that lead to low OER efficiency have been ascribed to its poor carrier mobility, low charge separation efficiency, and weak water oxidation kinetics at the electrode surface. $25-27$ Doping with electron-rich elements has been shown as an attractive approach to improve the overall OER performance. For example, several studies have demonstrated improved electron mobility and photoelectrochemical (PEC) performance by $\mathrm{W}$ - and Mo-doping, which has been attributed to the increased electron density. $\frac{1827-31}{1 n}$ contrast, other studies suggested that doping can introduce trap states and serve as recombination centres that enhance the electron-hole recombination, which may decompensate the improved carrier mobility. ${ }_{27,3233}$ Our recent studies on $\mathrm{W}$-doped $\mathrm{BiVO}_{4}$ photoanodes, however, suggested that the increased photocurrent upon $\mathrm{W}$ doping is largely attributed to the significant reduction of hole trap states, which inhibit the electron-hole pair recombination, while poor carrier mobility still remains as a limiting factor. ${ }^{34}$ These previous studies suggest that doping may exert multiple influences on the electronic properties and charge separation efficiency despite its promise for overall OER improvement.

In order to gain a deep understanding of the doping mechanism in $\mathrm{BiVO}_{4}$ photoanodes, it is necessary to examine the effect of doping on the carrier dynamics and OER performance using different dopants other than W. In this work, we investigate the effect of Mo doping on the morphology, carrier dynamics, and photocurrent performance of $\mathrm{BiVO}_{4}$ photoanodes, as well as the dependence on Mo concentration. The results from these fundamental studies were also evaluated in comparison with our previous findings on W-doped $\mathrm{BiVO}_{4}$ photoanodes. 


\section{Experimental}

\section{Materials}

Bismuth(III) nitrate $\left(\mathrm{Bi}\left(\mathrm{NO}_{3}\right)_{3} \cdot 5 \mathrm{H}_{2} \mathrm{O}\right.$, Ward's Science, Rochester, NY), vanadyl(IV) acetylacetonate $\left(\mathrm{C}_{10} \mathrm{H}_{14} \mathrm{O}_{5} \mathrm{~V}\right.$, Acros Organics, Geel, Belgium), ammonium molybdate tetrahydrate $\left(\left(\mathrm{NH}_{4}\right)_{6} \mathrm{Mo}_{7} \mathrm{O}_{24} \cdot 4 \mathrm{H}_{2} \mathrm{O}\right.$, Electron Microscopy Science, Hatfield, PA), acetic acid ( $\geq 99.7 \%$, Sigma Aldrich, Milwaukee, $\mathrm{WI})$, and acetylacetone $(>99.0 \%, \mathrm{TCl}$, Portland, OR) were used for film synthesis. Sodium sulfate $\left(\mathrm{Na}_{2} \mathrm{SO}_{4}\right.$, Ward's Science) and highly-polished $\mathrm{DI} \mathrm{H}_{2} \mathrm{O}$ showing $>16 \mathrm{Megaohm} \mathrm{cm}$ resistivity were used for electrolyte solution. FTO glass ( $2 \mathrm{~mm}$ thick, Solaronix, Aubonne, Switzerland) was cut to $1.25 \times$ $2.50 \mathrm{~cm}$ dimensions for electrode fabrication. Nitric acid (Sigma Aldrich) and hydrogen peroxide (30\%, J. T. Baker, Center Valley, PA) were used to make the piranha glass-etching solution.

\section{Synthesis of $\mathrm{Mo} / \mathrm{BiVO}_{4}$}

$\mathrm{BiVO}_{4}$ films were prepared as in our previous work by a solution-based method. 2.3 .34 The $\mathrm{Bi}$ and $\mathrm{V}$ precursors $(1: 1$ molar ratio) were dissolved in acetic acid (4 equivalents) and acetylacetone (1 equivalent), respectively, by sonication. Then, the two solutions were mixed and sonicated to make a $0.05 \mathrm{M} \mathrm{BiVO}_{4}$ stock solution with respect to $\mathrm{Bi}$ and $\mathrm{V}$. For undoped films, the stock solution was diluted to $0.04 \mathrm{M}$. For Mo-doped films, a $0.04 \mathrm{mM}$ solution of Mo precursor in acetic acid was prepared and then added to the $\mathrm{BiVO}_{4}$ stock solution in varying amounts (to obtain $0.2-1.8$ mol\% with respect to $\mathrm{BiVO}_{4}$ ) along with any necessary amount of acetic acid to bring the final concentration of $\mathrm{Mo} / \mathrm{BiVO}_{4}$ to 0.04 M. Films were prepared by drop-coating onto a piranha-etched glass substrate or cleaned FTO. The films were dried in air for 30 minutes and then calcined at $450^{\circ} \mathrm{C}$ for 90 minutes in air. After allowing to cool to room temperature slowly, films were then utilized for characterization.

\section{Characterization}

Steady-state UV-visible measurements were performed with an HP Agilent 8453 spectrometer. Scanning electron microscopy was performed with a JEOL JSM-6510LV operating in the secondary electron mode. X-ray diffraction (XRD) was performed using a Rigaku Miniflex II XRD diffractometer ( $\mathrm{Cu} K \alpha)$. XRD samples were prepared by removing samples from the glass substrate and grinding in methanol for 10 minutes, followed by drying in air.

\section{Transient absorption spectroscopy (TA)}

The TA spectrometer is based on a regenerative amplified Ti-Sapphire laser system (Solstice, $800 \mathrm{~nm},<100 \mathrm{fs}$ FWHM, $3.5 \mathrm{~mJ}$ per pulse, $1 \mathrm{kHz}$ repetition rate). The tunable $235-1150 \mathrm{~nm}$ pump is generated in TOPAS and the UV-visible probe is generated in a translated $\mathrm{CaF}_{2}$ window by white light generation. $315 \mathrm{~nm}$ pump pulse $(0.35 \mu \mathrm{J})$ was used for sample excitation. A Helios ultrafast spectrometer (Ultrafast Systems, LLC) was used for femtosecond TA measurements. The film sample was continuously translated to avoid sample degradation.

\section{Photoelectrochemical cell (PEC) measurements}

A custom three-electrode cell with a quartz window for electrode illumination was used for PEC measurements. A $\mathrm{Ag} / \mathrm{AgCl}(3 \mathrm{M} \mathrm{NaCl})$ reference electrode and a Pt wire counter electrode were used with a doped or un-doped $\mathrm{BiVO}_{4}-$ FTO working electrode in $0.1 \mathrm{M} \mathrm{Na}_{2} \mathrm{SO}_{4}(\mathrm{pH}$ 7) electrolyte. A $300 \mathrm{~W}$ xenon lamp with an IR-filter (one foot long water 
filter and an IR filter) and a UV-filter (>400 nm long-pass filter) output was used to illuminate the samples. The power density on the sample is $310 \mathrm{~mW} \mathrm{~cm}^{-2}$. The current density-voltage $(J-V)$ curve was recorded at a $25 \mathrm{mV} \mathrm{s}^{-1} \mathrm{scan}$ rate. The working electrode was illuminated from either front or back to observe photocurrent differences due to carrier transport.

\section{Results and discussion}

Although Mo-doped $\mathrm{BiVO}_{4}$ films with Mo concentrations varying from 0.2 to $5 \%$ were all synthesized, this work will focus only on the films with $0.2 \%, 1.0 \%$, and $1.8 \%$ Mo concentrations. This is because the films with Mo concentration above $2 \%$ show severe surface heterogeneity (Fig. S1a-c, ESI $\_$), preventing our carrier dynamics studies using transient absorption spectroscopy, which is one of the core studies in this work.

The morphologies of un-doped and $\mathrm{Mo-doped} \mathrm{BiVO}_{4}$ films with Mo concentrations varying from $0.2 \%, 1.0 \%$, to $1.8 \%$ were examined by SEM. As shown in Fig. 1 , a porous nanostructure was present in all $\mathrm{BiVO}_{4}$ films, while a rougher, more disordered structure was observed in the doped films with increasing Mo concentrations. The thickness of these films was controlled to be $\sim 2.8 \mu \mathrm{m}$ (Fig. S1d, ESI†). Fig. 2a compares the XRD patterns of undoped and Mo-doped $\mathrm{BiVO}_{4}$ films with different concentrations of Mo. With increasing Mo concentration, the splitting of the diffraction peaks at $35^{\circ}, 46^{\circ}$, and $58^{\circ}$ becomes less prominent. These results are consistent with previous literature data, ${ }^{34,35}$ indicating that the structure of $\mathrm{Mo} / \mathrm{BiVO}_{4}$ films slightly changes from monoclinic to a mixture of monoclinic and tetragonal phases. Previous studies have shown that the bandgap energies for $\mathrm{BiVO}_{4}$ films with monoclinic and tetragonal phases are $2.4 \mathrm{eV}$ and $2.9 \mathrm{eV}$, respectively. ${ }^{18}$ If Mo doping causes significant phase transfer from monoclinic to tetragonal structures, one would expect a peak shift in the UVvisible spectra of Mo-doped films compared to that of un-doped films. However, a negligible shift in the UVvisible spectra was observed between Mo-doped and un-doped $\mathrm{BiVO}_{4}$ films (Fig. $2 \mathrm{~b}$ ). These results, together with the less diffuse XRD patterns $\frac{36}{-}$ of Mo-doped films than those of the un-doped $\mathrm{BiVO}_{4}$ film, suggest that Mo-doped $\mathrm{BiVO}_{4}$ thin films mostly retain a monoclinic-scheelite structure.
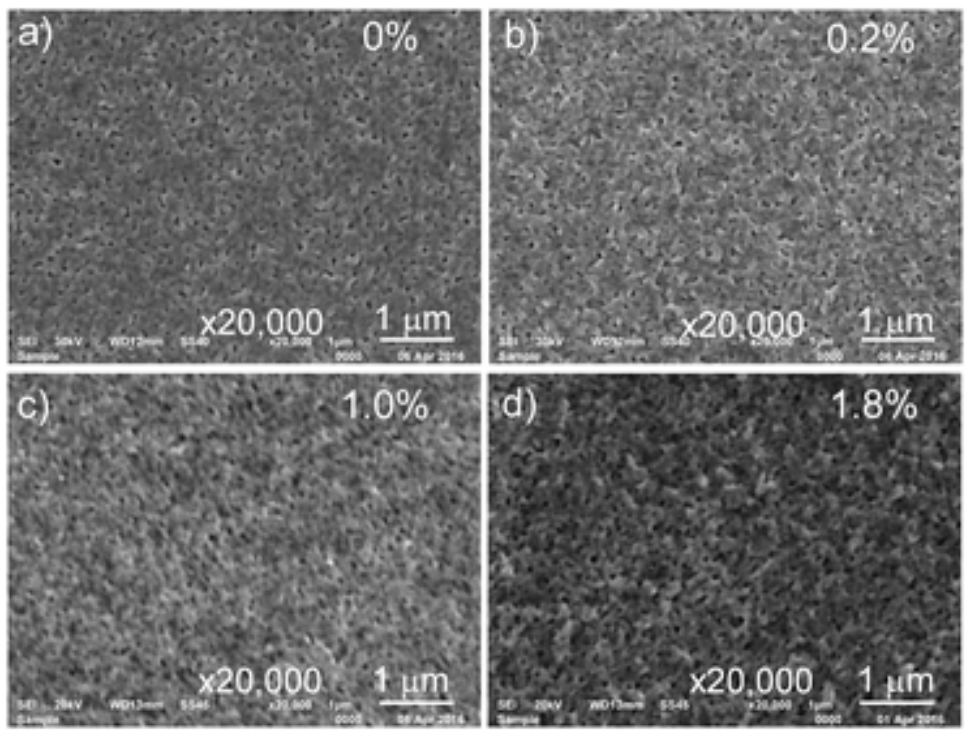

Fig. 1 SEM images of the un-doped BiVO ${ }_{4}$ film (a) and Mo/BiVO ${ }_{4}$ films with $0.2 \%(b), 1.0 \%(c)$, and $1.8 \%$ (d) Mo concentration. 

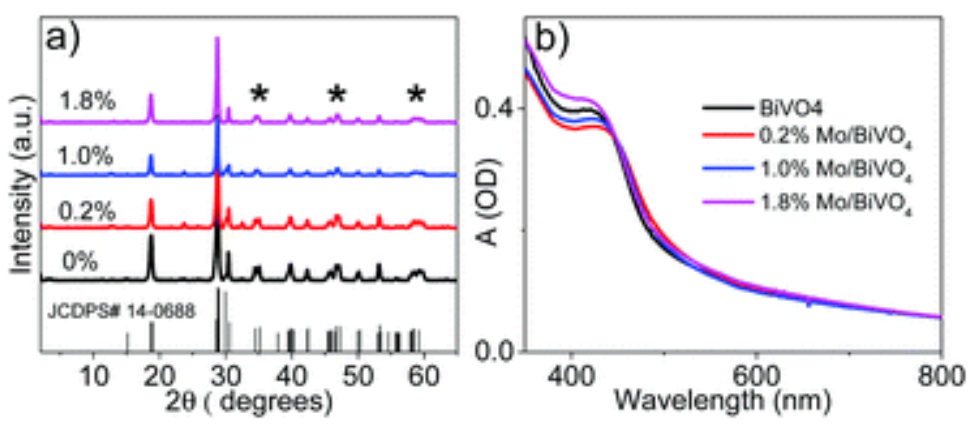

Fig. 2 (a) XRD patterns of the undoped and Mo-doped BiVO $\mathrm{B}_{4}$ films.

(b) UV-visible absorption spectra of un-doped and Mo-doped $\mathrm{BiVO}_{4}$ films.

The effect of Mo concentration on carrier dynamics was examined using femtosecond transient absorption spectroscopy (TA). Fig. 3a-c show the TA spectra of $\mathrm{Mo} / \mathrm{BiVO}_{4}$ films with $0.2 \%, 1.0 \%$, and $1.8 \%$ Mo concentrations, respectively. Similar to the spectral features of the un-doped $\mathrm{BiVO}_{4}$ film published previously, ${ }^{3437-}$ 40 all $\mathrm{Mo} / \mathrm{BiVO}_{4}$ samples exhibit four main features, including two absorption bands centered at $370 \mathrm{~nm}$ and 470 $\mathrm{nm}$, a broad featureless absorption $>550 \mathrm{~nm}$, and a negative feature that corresponds to the ground state (GS) bleach band. The three absorption bands exhibit a strong probe-wavelength-dependent feature (Fig. S2, ESI $\_$), which is consistent with our previous report on the hole trapping process and can be assigned to the trapped hole absorption. ${ }^{34}$ Fig. $3 \mathrm{~d}$ compares the initial TA spectra (at 0.5-1 ps delay time) of un-doped and Mo-doped $\mathrm{BiVO}_{4}$ films. These spectra have been normalized at the maximum of the GS bleach band for better comparison. It is immediately noticeable that the initial intensities of these hole absorption bands in the Mo-doped films are significantly reduced, where more reduction occurs in the films with higher Mo concentrations. These results together suggest that the intrinsic hole traps in the un-doped $\mathrm{BiVO}_{4}$ film are reduced due to Mo doping. 

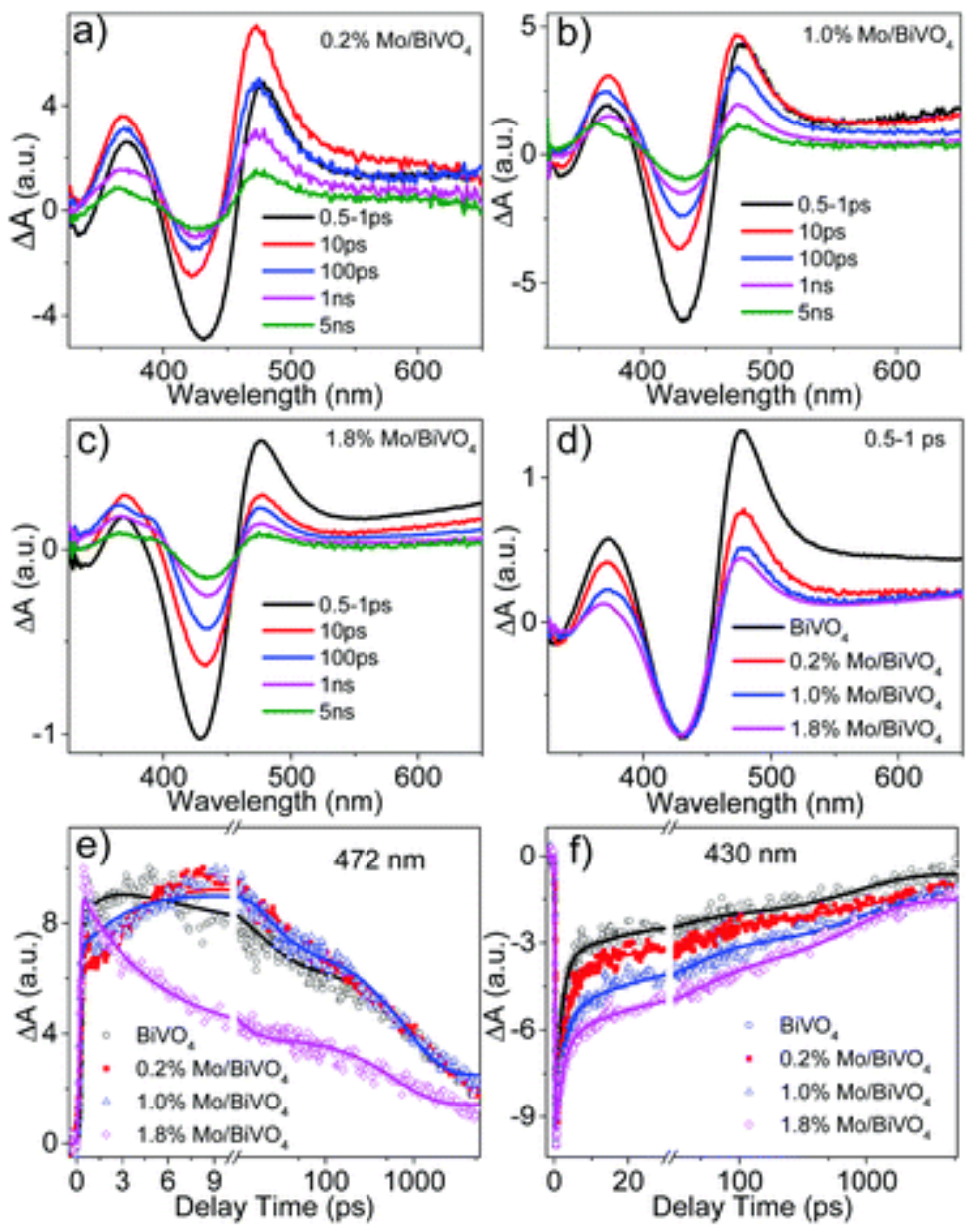

Fig. 3 Femtosecond TA spectra of $0.2 \% \mathrm{Mo} / \mathrm{BiVO}_{4}(\mathrm{a}), 1.0 \% \mathrm{Mo} / \mathrm{BiVO}_{4}$ (b), and $1.8 \% \mathrm{Mo} / \mathrm{BiVO}_{4}$ (c). (d) The comparison of TA spectra of un-doped and Mo-doped $\mathrm{BiVO}_{4}$ films with different doping concentrations at 0.5-1 ps time delay. The comparison of TA kinetic traces at $472 \mathrm{~nm}$ (e) and $430 \mathrm{~nm}$ (f) for un-doped and Mo-doped $\mathrm{BiVO}_{4}$ films with different Mo concentrations.

The reduction of hole traps in $\mathrm{Mo-doped} \mathrm{BiVO}_{4}$ films is further supported by the diminishing rising component at $472 \mathrm{~nm}$ which has been assigned to the hole trapping process previously. ${ }^{3739390}$ As shown in Fig. $3 \mathrm{e}$, a clear rising component was observed in the kinetic trace of the un-doped $\mathrm{BiVO}_{4}$ film. In contrast, this rising component becomes slower in $0.2 \% \mathrm{Mo} / \mathrm{BiVO}_{4}$ and $1.0 \% \mathrm{Mo} / \mathrm{BiVO}_{4}$ films, and eventually disappears in the $1.8 \%$ $\mathrm{Mo} / \mathrm{BiVO}_{4}$ film. These kinetic traces can be adequately fitted using a multi-exponential function. The kinetic traces for un-doped $\mathrm{BiVO}_{4}, 0.2 \% \mathrm{Mo} / \mathrm{BiVO}_{4}$, and $1.0 \% \mathrm{Mo} / \mathrm{BiVO}_{4}$ films can be fitted by a single rise component and three decay components, and the kinetic trace of $1.8 \% \mathrm{Mo} / \mathrm{BiVO}_{4}$ film can be fitted by three decay components. The fitting parameters and equations are summarized in Table 1 . The obtained time constants for the hole trapping process are $2.1 \mathrm{ps}, 4.2 \mathrm{ps}$, and $5.3 \mathrm{ps}$ for un-doped $\mathrm{BiVO}_{4}, 0.2 \% \mathrm{Mo} / \mathrm{BiVO}_{4}$, and $1.0 \%$ $\mathrm{Mo} / \mathrm{BiVO}_{4}$ films, respectively, suggesting a retarded hole trapping process with increasing Mo concentration. The remaining three decay components can be assigned to the charge recombination process between the trapped holes with electrons in the conduction band or electron trap states. $\underline{3740}$ 
Table 1 Fitting parameters for TA kinetics of un-doped $\mathrm{BiVO}_{4}$ and $\mathrm{Mo}$-doped $\mathrm{BiVO}_{4}$ films

\begin{tabular}{|c|c|c|c|c|c|c|c|}
\hline Probe & $\begin{array}{l}\text { Sample } \\
(\%)\end{array}$ & $\begin{array}{l}\tau_{1}, \operatorname{ps}\left(A_{1},\right. \\
\%)\end{array}$ & $\begin{array}{l}\tau_{2,}, \operatorname{ps}\left(A_{2},\right. \\
\%)\end{array}$ & $\begin{array}{l}\tau_{3}, \operatorname{ps}\left(A_{3},\right. \\
\%)\end{array}$ & $\tau, \mathbf{p}$ & $\left(A_{4}, \%\right)$ & \\
\hline & & & & & $\sum A_{i}$ & & \\
\hline The 43 & $0 \mathrm{~nm}$ kine & ic traces in & Fig. $3 f$ are $f$ & fitted with & & . The & he $472 \mathrm{~nm}$ kinetic traces in Fig. $3 \mathrm{e}$ are fitted \\
\hline & & & $\sum A_{j} \mathrm{e}^{-t / \tau_{i}}$ & $-\mathrm{e}^{-t / \tau}$ & & & \\
\hline & & with & $\operatorname{lin}_{i}$ & & indica & es the ri & rising component. \\
\hline $430 \mathrm{~nm}$ & 0 & $1.6(64)$ & $23(14.5)$ & $874(15.1)$ & $\gg 5$ & (6.4) & \\
\hline & 0.2 & $2.2(58.7)$ & 37.7 & 1130 & ns & $(115)$ & \\
\hline & & & $(17.0)$ & $(12.7)$ & & & \\
\hline & 1.0 & $2.2(45.5)$ & 35.3 & 1130 & & $(12.8)$ & \\
\hline & & & $(22.8)$ & (18.9) & & & \\
\hline & 1.8 & $2.2(37.2)$ & 49.1 & 1130 & & $(13.8)$ & \\
\hline & & & $(24.0)$ & $(24.2)$ & & & \\
\hline $472 \mathrm{~nm}$ & 0 & r2.1 (100) & 16.5 & $970(44.4)$ & $\gg 5$ & $(23.1)$ & \\
\hline & & & (32.5) & & ns & & \\
\hline & 0.2 & r4.2 (100) & 21.1 & 964 (40.9) & & (19.5) & \\
\hline & & & (39.6) & & & & \\
\hline & 1.0 & r5.3 (100) & 15.6 & 794 (39.7) & & $(20.6)$ & \\
\hline & & & (39.7) & & & & \\
\hline & 1.8 & & $5.0(57.6)$ & $628(26.8)$ & & (15.6) & \\
\hline
\end{tabular}

In addition to hole trapping dynamics, the effect of Mo doping on the electron dynamics was examined by probing the GS bleach kinetics. Fig. $3 \mathrm{f}$ compares the GS bleach recovery kinetics $(430 \mathrm{~nm})$ for un-doped $\mathrm{BiVO}_{4}$ and Mo-doped $\mathrm{BiVO}_{4}$ films. These kinetic traces can all be fit by four-exponential-decay functions with their parameters listed in Table 1. The fastest time component ( $\tau_{1}$ in Table 1), likely resulting from an electron trapping process, increases from $1.6 \mathrm{ps}$ in the un-doped $\mathrm{BiVO}_{4}$ film to $2.2 \mathrm{ps}$ in $\mathrm{Mo}_{\text {-doped }} \mathrm{BiVO}_{4}$ films. The increase of time constant is accompanied by decreasing amplitude, suggesting the reduction of the electron trapping process. In addition, the overall GS recovery kinetics becomes slower in Mo-doped $\mathrm{BiVO}_{4}$ films, following the order of $1.8 \% \mathrm{Mo} / \mathrm{BiVO}_{4}<1.0 \% \mathrm{Mo} / \mathrm{BiVO}_{4}<0.2 \%$ $\mathrm{Mo} / \mathrm{BiVO}_{4}<$ un-doped $\mathrm{BiVO}_{4}$, suggesting that the overall electron-hole recombination is inhibited with the increase of Mo concentration. These results imply that Mo doping altered the nature of trap states in $\mathrm{BiVO}_{4}$ films through diminishing the hole and electron trapping processes, which together elongate the electron-hole pair lifetime. Due to the presence of the long decay component ( $\gg 5 \mathrm{~ns}$ ) which is beyond the TA time window, the electron-hole lifetime cannot be quantitatively determined from these fitting parameters. Instead, the electron-hole lifetime was estimated 
from the half-recovery time of GS bleach, the time when the GS bleach recovers to $50 \%$. The half-recovery lifetimes were $2.9,6.0,17.2$, and 48.5 ps for un-doped $\mathrm{BiVO}_{4}, 0.2 \% \mathrm{Mo} / \mathrm{BiVO}_{4}, 1.0 \% \mathrm{Mo} / \mathrm{BiVO}_{4}$, and $1.8 \% \mathrm{Mo} / \mathrm{BiVO}_{4}$ films, respectively.

In addition to the effect of Mo doping on the carrier dynamics of $\mathrm{BiVO}_{4}$ films, the dependence of carrier mobility in $\mathrm{BiVO}_{4}$ films on Mo concentration was also examined using linear sweep voltammetry performed under visible light illumination. It has been shown that the difference in photocurrents between back- and front-illumination is related to the electron mobility because the back-illumination generates excitons close to the FTO backcontact whereas front-illumination generates excitons primarily at the surface where the electrons need to reach the back contact of the electrode. ${ }^{41-43}$ Therefore, the higher photocurrent from back-illumination than from front-illumination suggests that slow electron transport is one of the limiting factors for photocurrent generation. For the un-doped $\mathrm{BiVO}_{4}$ sample ( $\underline{\text { Fig. 4a) }}$, there is a significant difference in photocurrent when illuminated from the front compared to from the back during photocatalysis, where much higher photocurrent under back-side illumination was observed, suggesting poor electron mobility in the un-doped $\mathrm{BiVO}_{4}$ sample. It is noticeable that this difference becomes smaller with increasing Mo doping level (Fig. 4b-d), suggesting that electron mobility improves with increasing Mo doping. Indeed, little difference was observed between frontand back-illumination for the $1.8 \% \mathrm{Mo} / \mathrm{BiVO}_{4}$ film (Fig. 4d), indicating that electron mobility is no longer a limiting factor for OER performance with the addition of $1.8 \%$ Mo dopant. These findings clearly demonstrate that electron mobility in $\mathrm{BiVO}_{4}$ photoanodes is significantly improved upon Mo doping.
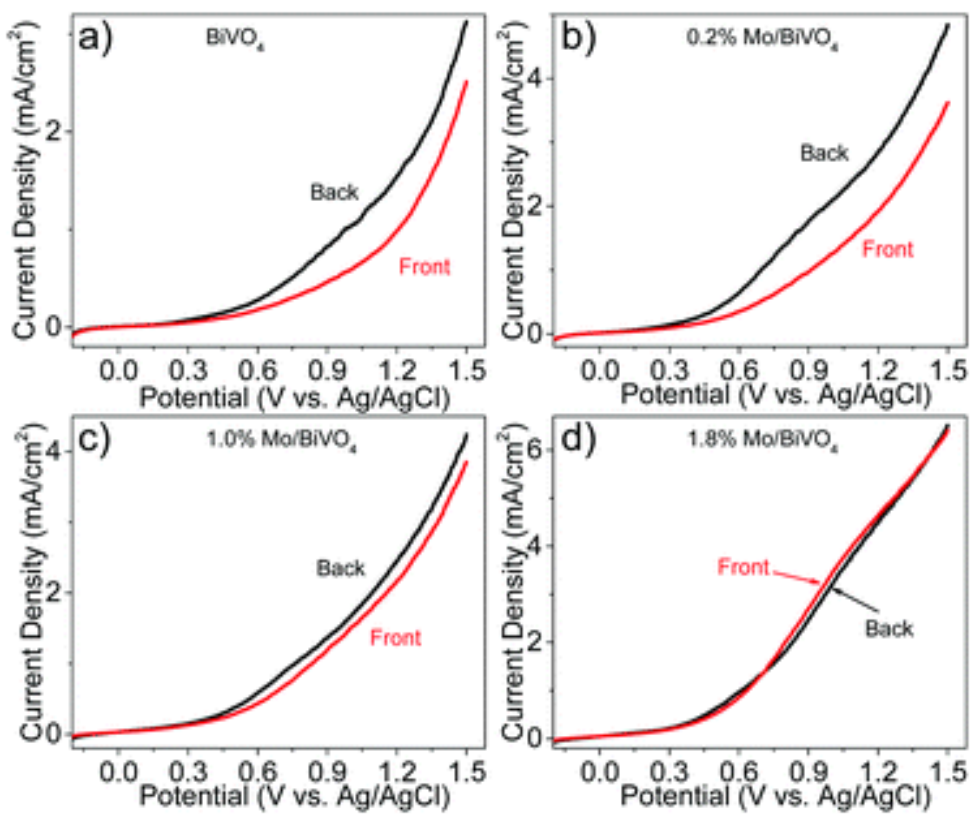

Fig. 4 The comparison of photocurrent from back-side- and front-side-illumination for un-doped $\mathrm{BiVO}_{4}(\mathrm{a}), 0.2 \% \mathrm{Mo} / \mathrm{BiVO}_{4}(\mathrm{~b}), 1.0 \% \mathrm{Mo} / \mathrm{BiVO}_{4}(\mathrm{c})$, and $1.8 \% \mathrm{Mo} / \mathrm{BiVO}_{4}$ (d) thin films.

With the understanding of the effect of Mo doping on the carrier dynamics and electron mobility of $\mathrm{BiVO}_{4}$ photoanodes, we now turn to evaluate the correlation of these properties with OER performance. Fig. $\underline{5}$ compares the OER photocurrents of the un-doped $\mathrm{BiVO}_{4}$ film and Mo-doped $\mathrm{BiVO}_{4}$ films with different $\mathrm{Mo}$ 
concentrations under back-side illumination. Although not shown, there was negligible current observed for all samples without light illumination. In contrast, under light illumination, it is immediately apparent that Modoped photoanodes produce a higher photocurrent than the un-doped $\mathrm{BiVO}_{4}$ photoanode, beginning to diverge at overpotentials as low as $0.3 \mathrm{~V}$ vs. $\mathrm{Ag} / \mathrm{AgCl}$. Despite the little difference in photocurrent between $0.2 \%$ and $1.0 \% \mathrm{Mo} / \mathrm{BiVO}_{4}$, the overall trend for photocurrent shows an increase with increasing doping concentration, where the sample with the highest doping level $\left(1.8 \% \mathrm{Mo} / \mathrm{BiVO}_{4}\right)$ shows the maximum photocurrent.

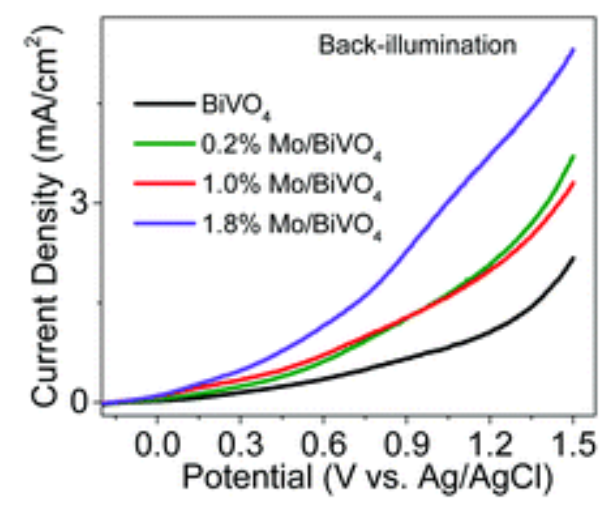

Fig. 5 Photocurrent comparison of un-doped $\mathrm{BiVO}_{4}$ and Mo-doped $\mathrm{BiVO}_{4}$ photoanodes under back-illumination.

Previous studies have shown that the $\mathrm{PEC}$ performance of $\mathrm{BiVO}_{4}$ photoanodes is strongly dependent on their crystal structure. Kudo and coworkers have found that $\mathrm{BiVO}_{4}$ photoanodes with a monoclinic scheelite structure demonstrated much higher photocatalytic activity than those with a tetragonal structure, which has been mainly attributed to the enhanced light absorption of the former with a bandgap of $2.4 \mathrm{eV}$, while the latter have a bandgap of $2.9 \mathrm{eV} .{ }_{18.22} \mathrm{According}$ to these findings, one would expect that the change in the $\mathrm{BiVO}_{4}$ structure from monoclinic scheelite to tetragonal due to Mo doping would reduce its photocatalytic activity. However, our work along with some previous studies ${ }^{34.35}$ showed improved PEC performance regardless of the change in the crystal structure. Given that other factors in addition to the crystal structure can also influence the PEC performance, and doping only causes small changes in the crystal structure, we believe that the much higher photocurrent in the Mo-doped films is mainly ascribed to the improved electron mobility due to increasing electron density and increased carrier lifetime due to diminishing electron and hole trap states, which likely compensates the negative effect resulting from crystal structure change.

Very recently, we have reported the origin of improved charge separation and OER performance of $\mathrm{BiVO}_{4}$ photoanodes to be $\mathrm{W}$ doping. ${ }^{34}$ The results showed that the improved photocurrent of $\mathrm{BiVO}_{4}$ is mainly attributed to the inhibited electron-hole recombination due to the reduction of trap states, while the carrier mobility has little contribution. In contrast, the current study on Mo-doping effect demonstrates that the significant improvement in photocurrent can be ascribed to both the increased carrier mobility and charge separation efficiency. In order to better understand the doping mechanism in $\mathrm{BiVO}_{4}$ photoanodes and identify the appropriate dopants for optimum OER performance, it is necessary to compare the origin of the doping effect on the electronic structure, carrier dynamics and photocurrent performance of $\mathrm{BiVO}_{4}$ photoanodes resulting from Mo and $\mathrm{W}$ dopants. 
Fig. 6a compares the XRD patterns of $1.8 \% \mathrm{~W} / \mathrm{BiVO}_{4}$ and $1.8 \% \mathrm{Mo} / \mathrm{BiVO}_{4}$ films. Slightly sharper diffraction peaks at $35^{\circ}, 46^{\circ}$, and $58^{\circ}$ were observed for the $\mathrm{W} / \mathrm{BiVO}_{4}$ film than for the $\mathrm{Mo} / \mathrm{BiVO}_{4}$ film, indicating that $\mathrm{Mo} / \mathrm{BiVO}_{4}$ more likely retains the monoclinic-scheelite phase than the $\mathrm{W} / \mathrm{BiVO}_{4}$ film. This finding was further confirmed by their UV-visible spectra, where the spectrum of the $\mathrm{W} / \mathrm{BiVO}_{4}$ film is found to be more blue-shifted

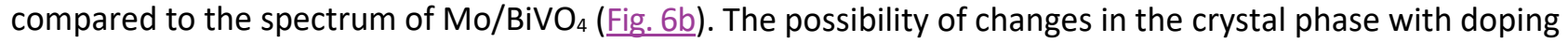
necessitates the structural analysis by X-ray absorption spectroscopy, in which the local structure of individual atoms can be probed and determined. As shown in Fig. S3-S5 (ESI+), the local structure at both $\mathrm{Bi}$ and $\mathrm{V}$ centers, probed by $\mathrm{X}$-ray absorption spectroscopy (XAS), shows a negligible change in both the oxidation state and the local geometry between $\mathrm{W} / \mathrm{BiVO}_{4}$ and $\mathrm{Mo} / \mathrm{BiVO}_{4}$, although their local structures are different from that of the un-doped $\mathrm{BiVO}_{4}$ film. ${ }^{34}$ These results imply that the change in the ground state electronic structure of $\mathrm{BiVO}_{4}$ films due to $\mathrm{W}$ or Mo doping are insignificant despite the slightly more monoclinic-scheelite phase in $\mathrm{Mo} / \mathrm{BiVO}_{4}$ films than in $\mathrm{W} / \mathrm{BiVO}_{4}$ films.
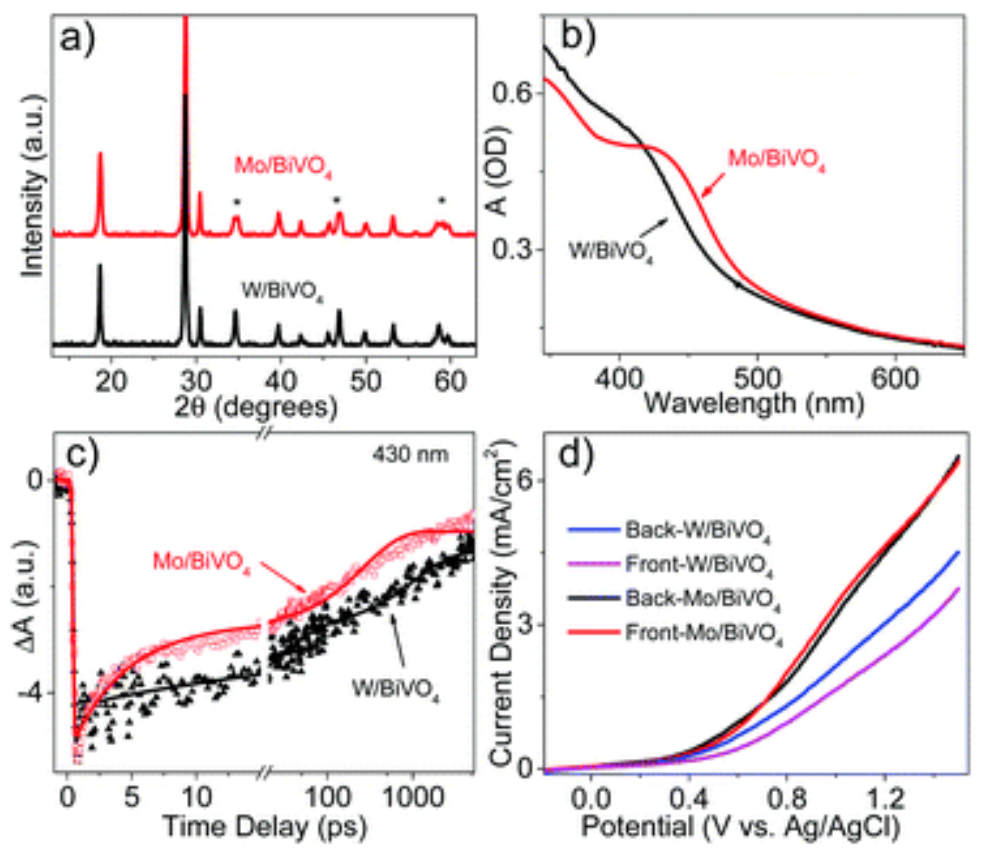

Fig. 6 The comparison of XRD patterns (a), UV-visible absorption spectra (b), ground state bleach kinetics at $430 \mathrm{~nm}$ (c), and photocurrents (d) of $1.8 \% \mathrm{Mo} / \mathrm{BiVO}_{4}$ and $1.8 \% \mathrm{~W} / \mathrm{BiVO}_{4}$ films.

In addition to their ground state electronic structure, the carrier dynamics of $1.8 \% \mathrm{~W} / \mathrm{BiVO}_{4}$ and $1.8 \%$ $\mathrm{Mo} / \mathrm{BiVO}_{4}$ films were also compared. As indicated by the noteworthy reduction of the initial amplitude of TA spectra of both doped $\mathrm{BiVO}_{4}$ films compared to the un-doped one (Fig. S6, ESI \pm ), doping caused a substantial reduction of hole traps in the doped films. However, the GS bleach recovery in $1.8 \% \mathrm{Mo} / \mathrm{BiVO}_{4}$ appears to be faster than that in $1.8 \% \mathrm{~W}^{-\mathrm{BiVO}_{4}}$ (Fig. $6 \mathrm{C}$ ), suggesting enhanced electron-hole recombination in the former. This result conflicts with the photocurrent measurement, where the photocurrent generated by $1.8 \%$ $\mathrm{Mo} / \mathrm{BiVO}_{4}$ photoanode is much higher than that of $1.8 \% \mathrm{~W} \mathrm{BiVO}_{4}$ photoanode (Fig. $6 \mathrm{~d}$ ). Given that Mo doping caused significantly increased electron mobility in $1.8 \% \mathrm{Mo} / \mathrm{BiVO}_{4}$ photoanode while $\mathrm{W}$ doping caused a limited improvement in electron mobility in $1.8 \% \mathrm{~W} / \mathrm{BiVO}_{4}$ photoanode, we therefore attribute the much higher 
photocurrent in the former to the increased electron mobility upon Mo doping, which compensates its less efficient charge separation efficiency.

\section{Conclusions}

In conclusion, the effect of Mo doping on the carrier dynamics and OER performance of $\mathrm{BiVO}_{4}$ photoanodes was investigated. Using transient absorption spectroscopy, we show that both electron and hole traps are reduced upon Mo doping, inhibiting the electron-hole recombination. The studies of photocurrent measurement using linear sweep voltammetry reveal an improved photocurrent with increasing Mo concentration, which is accompanied by the significantly enhanced electron mobility. Compared to $\mathrm{W}$-doped $\mathrm{BiVO}_{4}$ photoanodes, despite the enhanced electronhole recombination in $\mathrm{Mo} / \mathrm{BiVO}_{4}$ photoanodes, the OER photocurrent is much higher in the latter, which can be attributed to the significantly improved electron mobility in $\mathrm{Mo} / \mathrm{BiVO}_{4}$ photoanodes, compensating the less efficient charge separation efficiency. These findings provide further understanding of the doping physics in $\mathrm{BiVO}_{4}$ photoanodes and will provide important insights into the optimization of OER performance by identifying appropriate dopants and dopant concentrations.

\section{Acknowledgements}

This work was supported by Marquette University New Faculty Startup Fund and Regular Research Grant. Use of the Advanced Photon Source in Argonne National Laboratory was supported by the U.S. Department of Energy, Office of Science, Office of Basic Energy Sciences, under award No. DE-AC02-06CH11357.

\section{References}

1. S. Y. Reece, J. A. Hamel, K. Sung, T. D. Jarvi, A. J. Esswein, J. J. H. Pijpers and D. G. Nocera, Science, 2011, 334, 645-648.

2. M. Gratzel, Nature, 2001, 414, 338-344

3. M. G. Walter, E. L. Warren, J. R. McKone, S. W. Boettcher, Q. X. Mi, E. A. Santori and N. S. Lewis, Chem. Rev., 2010, 110, 6446-6473

4. W. J. Youngblood, S. H. A. Lee, Y. Kobayashi, E. A. Hernandez-Pagan, P. G. Hoertz, T. A. Moore, A. L. Moore, D. Gust and T. E. Mallouk, J. Am. Chem. Soc., 2009, 131, 926-927.

5. D. Gust, T. A. Moore and A. L. Moore, Acc. Chem. Res., 2009, 42, 1890-1898

6. A. Fujishima and K. Honda, Nature, 1972, 238, 2

7. M. W. Kanan and D. G. Nocera, Science, 2008, 321, 1072-1075.

8. F. D. Lin and S. W. Boettcher, Nat. Mater., 2014, 13, 81-86.

9. Y. J. Lin, S. Zhou, X. H. Liu, S. Sheehan and D. W. Wang, J. Am. Chem. Soc., 2009, 131, 2772-2773 .

10. Y. Tian and T. Tatsuma, J. Am. Chem. Soc., 2005, 127, 7632-7637.

11. M. Ni, M. K. H. Leung, D. Y. C. Leung and K. Sumathy, Renewable Sustainable Energy Rev., 2007, 11, 401-425.

12. I. S. Cho, M. Logar, C. H. Lee, L. L. Cai, F. B. Prinz and X. L. Zheng, Nano Lett., 2014, 14, 24-31 .

13. H. Dotan, K. Sivula, M. Gratzel, A. Rothschild and S. C. Warren, Energy Environ. Sci., 2011, 4, 958-964.

14. M. Bar, L. Weinhardt, B. Marsen, B. Cole, N. Gaillard, E. Miller and C. Heske, Appl. Phys. Lett., 2010, 96, 032107

15. Q. X. Mi, Y. Ping, Y. Li, B. F. Cao, B. S. Brunschwig, P. G. Khalifah, G. A. Galli, H. B. Gray and N. S. Lewis, J. Am. Chem. Soc., 2012,134, 18318-18324 .

16. J. W. Jang, C. Du, Y. Ye, Y. Lin, X. Yao, J. Thorne, E. Liu and G. McMahon, Nat. Commun., 2015, 6, 7447-7451

17. Y. Park, K. J. McDonald and K. S. Choi, Chem. Soc. Rev., 2013, 42, 2321-2337

18. A. Kudo, K. Omori and H. Kato, J. Am. Chem. Soc., 1999, 121, 11459-11467.

19. F. F. Abdi, L. H. Han, A. H. M. Smets, M. Zeman, B. Dam and R. van de Krol, Nat. Commun., 2013, 4, 2195. 
20. K. Sayama, A. Nomura, T. Arai, T. Sugita, R. Abe, M. Yanagida, T. Oi, Y. Iwasaki, Y. Abe and H. Sugihara, J. Phys. Chem. B, 2006,110, 11352-11360.

21. H. M. Luo, A. H. Mueller, T. M. McCleskey, A. K. Burrell, E. Bauer and Q. X. Jia, J. Phys. Chem. C, 2008, 112, 6099-6102.

22. A. Iwase and A. Kudo, J. Mater. Chem., 2010, 20, 7536-7542

23. A. Walsh, Y. Yan, M. N. Huda, M. M. Al-Jassim and S. H. Wei, Chem. Mater., 2009, 21, 547-551 .

24. S. P. Berglund, D. W. Flaherty, N. T. Hahn, A. J. Bard and C. B. Mullins, J. Phys. Chem. C, 2011, 115, 3794-3802 .

25. H. Ye, J. Lee, J. S. Jang and A. J. Bard, J. Phys. Chem. C, 2010, 114, 13322-13328.

26. P. M. Rao, L. L. Cai, C. Liu, I. S. Cho, C. H. Lee, J. M. Weisse, P. D. Yang and X. L. Zheng, Nano Lett., 2014, 14, 1099-1105.

27. F. F. Abdi, T. J. Savenije, M. M. May, B. Dam and R. van de Krol, J. Phys. Chem. Lett., 2013, 4, 2752-2757 .

28. W. J. Luo, Z. S. Yang, Z. S. Li, J. Y. Zhang, J. G. Liu, Z. Y. Zhao, Z. Q. Wang, S. C. Yan, T. Yu and Z. G. Zou, Energy Environ. Sci., 2011, 4, 4046-4051.

29. H. S. Park, K. E. Kweon, H. Ye, E. Paek, G. S. Hwang and A. J. Bard, J. Phys. Chem. C, 2011, 115, 17870-17879 .

30. S. P. Berglund, A. J. E. Rettie, S. Hoang and C. B. Mullins, Phys. Chem. Chem. Phys., 2012, 14, 7065-7075.

31. K. P. S. Parmar, H. J. Kang, A. Bist, P. Dua, J. S. Jang and J. S. Lee, ChemSusChem, 2012, 5, 1926-1934

32. W. J. Luo, Z. S. Li, T. Yu and Z. G. Zou, J. Phys. Chem. C, 2012, 116, 5076-5081 .

33. K. E. Karakitsou and X. E. Verykios, J. Phys. Chem., 1993, 97, 1184-1189.

34. B. Pattengale, J. Ludwig and J. Huang, J. Phys. Chem. C, 2016, 120, 1421-1427.

35. A. J. E. Rettie, H. C. Lee, L. G. Marshall, J. F. Lin, C. Capan, J. Lindemuth, J. S. McCloy, J. S. Zhou, A. J. Bard and C. B. Mullins, J. Am. Chem. Soc., 2013, 135, 11389-11396.

36. S. M. Thalluri, S. Hernandez, S. Bensaid, G. Saracco and N. Russo, Appl. Catal., B, 2016, 180, 630-636 .

37. N. Aiga, Q. X. Jia, K. Watanabe, A. Kudo, T. Sugimoto and Y. Matsumoto, J. Phys. Chem. C, 2013, 117, 98819886.

38. Y. M. Ma, S. R. Pendlebury, A. Reynal, F. Le Formal and J. R. Durrant, Chem. Sci., 2014, 5, 2964-2973 .

39. J. Ravensbergen, F. F. Abdi, J. H. van Santen, R. N. Frese, B. Dam, R. van de Krol and J. T. M. Kennis, J. Phys. Chem. C, 2014,118, 27793-27800.

40. I. Grigioni, K. G. Stamplecoskie, E. Selli and P. V. Kamat, J. Phys. Chem. C, 2015, 119, 20792-20800 .

41. D. K. Zhong, S. Choi and D. R. Gamelin, J. Am. Chem. Soc., 2011, 133, 18370-18377 .

42. F. F. Abdi and R. van de Krol, J. Phys. Chem. C, 2012, 116, 9398-9404 .

43. J. A. Seabold and K. S. Choi, J. Am. Chem. Soc., 2012, 134, 2186-2192. 